\title{
Tips for GP trainees working in psychiatry
}

Many doctors approach psychiatry with a sense of trepidation and, occasionally, fear. The aim of this article is to give some concrete advice to help trainees to relax and enjoy this fascinating rotation. A spell in psychiatry has the potential to be one of the most useful rotations on the general practice training scheme. Much of psychiatry is now managed in the community and so will form a significant part of your work following qualification. As increasing pressure comes to bear on mental health trusts to cut costs and close inpatient beds this is only likely to increase. When people suffer mental health issues it is very often the GP who is their first port of call, and so a good working knowledge of the area, as well as insight into the mechanisms and frameworks of secondary care, is an asset. During the job, you will also have the opportunities and time to develop your communication skills, occasionally in crisis situations.

As with all rotations, it is imperative that you are organised and clear about what you want to experience and get out of your time in psychiatry. It is up to you to make this happen, but presenting your clinical supervisor with a brief written PDP at the start of the rotation shows that you are a motivated and positive individual and increases their motivation to teach you and ensure you are getting the relevant experience you need. Psychiatry is very different from many of the other jobs on the training rotation and requires a different approach but should provide the trainee with invaluable experience for their future careers as GPs. It is hoped that the following advice may help increase your enjoyment of the job.

1. Treat the patients with dignity at all times. You will never regret it.

2. Try not to be afraid of psychiatry or psychiatric patients, you cannot catch madness.

3. The psychiatric multidisciplinary team is less hierarchical than a standard medical team - respect this. Recognising the skills and knowledge of the multidisciplinary team will enhance your ability to care for your patients.

4. Most psychiatric units are very different from hospital wards. Remember that many psychiatric nurses are not trained or experienced in spotting medical problems and you should not expect them to... that's your job.

5. Know how neuroleptic malignant syndrome presents and how to manage it.

6. Attend a breakaway training course that shows you physical techniques to remove yourself from violent encounters. Hopefully you will never have to use the skills, but you'll never regret having them, even when you have finished psychiatry and doing other jobs.

7. Direct confrontation and shouting at agitated patients rarely calms the situation or leads to a favourable result. Always try to de-escalate tense situations. Offer oral medication before resorting to the intramuscular route.

8. Always write up rapid tranquilisation on the 'as required' section of the patient's drug chart on all admissions. Write oral and intramuscular routes separately and remember that some drugs (for example, haloperidol) have different 24-hour maximum doses for oral and intramuscular routes.

9. Check if a patient has been prescribed antipsychotics before.

10. Become fluent in the performance and recording of the mental state examination, you'll be doing a lot of it! Take a crib sheet with the headings on for the first few oncalls and clinics till it becomes second nature (as it will).

11. Take drug charts and all admission forms to A\&E when oncall in case you need to admit a patient. That way you can take care of all the paperwork at once.
12. Make sure you know which consultant is oncall and their contact details. Find this out at the start of the shift rather than out-of-hours when you need to speak to them urgently.

13. Initially you should be discussing all patients you see with a psychiatry consultant.

14. Always do a risk assessment. Always ask about suicidal ideation, thoughts of self-harm and thoughts of harm towards others. Other domains of risk include vulnerability from others, selfneglect and psychosis. Remember that not all risks are predictable.

15. If you ever think you need to call the consultant, do. But before you do, formulate the patient using the biopsychosocial precipitating/ predisposing/maintaining matrix. Be clear what the main areas of risk are, and how likely you think they are to happen.

16. Learn the process, and become familiar with the paperwork of detaining patients under section 5:2 of the Mental Health Act. When you need to do this you don't want to be learning on the job and paperwork errors cause great headaches for the entire trust.

17. Try to de-escalate situations before resorting to the Mental Health Act. If patients feel they have been listened to they can often be persuaded to stay informally.

18. Think about any child protection issues.

19. Get in the habit of taking a personal alarm with you. Know how to use it. Know how to provide assistance to others who need it.

20. Do not get involved in restraint unless you have proper training. Without it, restraint is very dangerous for the patient (and for you).

21. People with personality disorders can be difficult to manage. They can bring up polarised feelings within you, and between your team (technically known 
as splitting). Try and get some exposure to the STEPPS programme for borderline personality disorder.

22. Learn some cognitive behavioural therapy (CBT). If you can't attend a course get some teaching from your team psychologist. GPs pay good money to go on courses to get this experience! Make sure this training finds its way onto your CV.

23. Listen to the nurses! They spend much much longer with the patients than you do and have a wealth of knowledge and experience that they are usually happy to share.

24. Try to do some home visits with the community psychiatric nurses if appropriate.

25. Let it be known that you are interested in seeing some mental health assessments performed by the consultants. This will give you insight into the process which will be useful when you are a GP.

26. Learn how to manage the core psychiatric diagnoses such as depression, schizophrenia, and bipolar disorder.

27. Get a good chart to guide you when changing patients medications.

28. Try to become familiar with the sideeffect profile of common or significant psychotropic medications such as lithium, clozapine, the antipsychotics, and antidepressants.

29. Learn to spot extrapyramidal side effects. Always write up procycladine 'as required' for patients who are on antipsychotics.

30.The Maudsley Guidelines are a fantastic resource.

31. Don't let your physical medicine slip - some psychiatrists have been out of the general hospital for long enough to feel deskilled in managing physical (that is, non-mental health) problems. Your team will often be looking for your leadership in this area.

32. Remember to consider organic causes of psychiatric presentations.
33. Mental health stigma and prejudice is real and widespread. Make sure you are not part of the problem.

34. Treating people with alcohol issues is difficult. Accept that until they become motivated, you won't cure them.

35. Make sure you laugh. Psychiatry is emotionally demanding and without this release you will really struggle.

36. Attend the Balint group, engage with the Balint group, write about the Balint group in your eportfolio (educational supervisors love it!).

37. Always do a physical exam and blood tests when admitting a patient unless they really are too agitated. Try not to leave it to someone else to do the next day. It would be awful to miss a medical problem that could result in significant harm to the patient.

38. Regardless of your placement try to sit in on or get experience of Child and Adolescent Mental Health Services, Working Age Mental Health Services and Older People's Mental Health Services, liaison psychiatry, eating disorder services, and any other specialist clinics that you think will be useful or interesting.

39. Remember that disinhibited older patients with dementia can be the population most prone to assaulting staff.

40. When starting patients on SSRIs warn them that anxiety can get worse in the initial period. Also warn them that positive effects generally take at least 2 weeks and often a month to kick in.

$41.1 \mathrm{mg}$ lorazepam $=5-10 \mathrm{mg}$ diazepam. ${ }^{2}$

42. Always warn patients benzodiazepines are addictive (and antidepressents aren't).

43. Make your consultant's secretary your best friend. Make tea, offer biscuits, make them want to work for you.

Matthew Burkes, Laurine Hanna and James Woollard

\section{REFERENCES}

1. Taylor D, Paton C, Kapur S. The Maudsley Prescribing Guidelines. 10th edn. London: Informa Healthcare, 2009.

2. Joint Formulary Committee. British National Formulary, No 60. London: British Medical Association and Royal Pharmaceutical Society of Great Britain, 2010.

DOI: 10.3399/bjgp11X556407 